\title{
Vibration-Based Damage Identification and Condition Monitoring of Metro Trains: Warsaw Metro Case Study
}

\author{
Alicja Kowalska-Koczwara $\mathbb{D}^{1},{ }^{1}$ Filip Pachla $\mathbb{D}^{1},{ }^{1}$ Piotr Stecz, \\ Krzysztof Stypuła, ${ }^{1}$ Tadeusz Tatara, ${ }^{1}$ Jerzy Lejk, ${ }^{2}$ and Marek Sokołowski ${ }^{2}$ \\ ${ }^{1}$ Cracow University of Technology, Warszawska 24 St., 31-155 Cracow, Poland \\ ${ }^{2}$ Metro Warszawskie Sp. z o. o., Wilczy Dół 5 St., 02-798 Warsaw, Poland \\ Correspondence should be addressed to Filip Pachla; fpachla@pk.edu.pl
}

Received 18 December 2017; Accepted 31 March 2018; Published 10 May 2018

Academic Editor: Rafał Burdzik

Copyright (C) 2018 Alicja Kowalska-Koczwara et al. This is an open access article distributed under the Creative Commons Attribution License, which permits unrestricted use, distribution, and reproduction in any medium, provided the original work is properly cited.

\begin{abstract}
The work concerns the monitoring of the technical condition of metro trains. For this purpose, a vibration monitoring system installed in buildings in the vicinity of the underground is used. Based on measured vibrations buildings, the identification of technical condition in metro trains is conducted. The results of measurements from the system are also used to assess the impact of vibrations on people staying in buildings through the WODL ratio. Exceeding the assumed levels of the WODL ratio is the basis for repairing trains by turning wheels. Statistical analysis of the data was implemented and trends for particular time periods of measurements were shown. With the entered monitoring system and the introduced WODL index thresholds, it is possible to better plan the costs associated with the repair and replacement of wheels of rolling stock, where there are large values of radial runout. According to the introduced monitoring procedure, the number of complaints from residents decreased and the comfort of their lives improved.
\end{abstract}

\section{Introduction}

The vibration monitoring system in civil engineering mainly concerns two aspects: structural health monitoring [1-4] and ambient or seismic vibration monitoring [5-7]. There are relatively few articles that address the issue of monitoring vibrations in buildings from existing road, rail, or metro infrastructure. Investigators are concerned about short-term monitoring [8] or vibrations, which are measured on the ground [9] or in the tunnel [10] and eventually the building model is excited by recorded signals [11]. It is worth noting that the building structure exposed to vibrations is investigated by researches, while human perception of vibrations is a decisive parameter of evaluation. People are more sensitive to vibrations than building structures are, especially when these vibrations occur often, although they are not very strong. These kinds of situations occur in buildings located close to the road, railway, tramway, or subway. Often, during the designing or the building of these urban infrastructures, human perception of vibrations throughout these buildings located is not taken into account $[12,13]$. Furthermore, the exploitation of this parameter of evaluation is not monitored. Meanwhile, this existing infrastructure has become older, sometimes infrastructures conditions change (due to traffic increases or changing of train or tram types), and some of its elements become slightly damaged, all of which can influence human perception of vibrations. It is impossible to change the location of an existing urban infrastructure. The vibration monitoring system can provide solutions to the necessary infrastructure design (i.e., by introducing additional vibroinsulation $[14,15])$. Some small repairs in the existing infrastructure system are sufficient to ensure vibrational comfort in buildings located nearby.

A few years after the opening of its first metro line, Warsaw Metro owners observed a growing number of complaints from the residents of neighbouring buildings. This prompted 


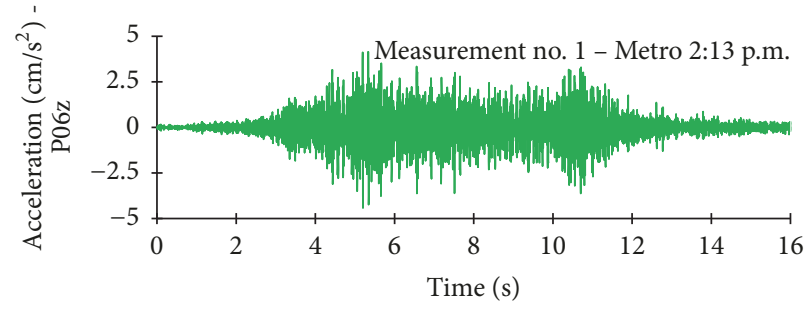

(a)

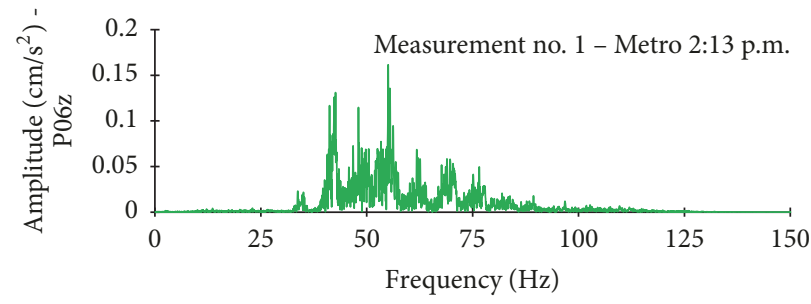

(b)

FIGURE 1: Exemplary record of vertical component of the floor apartment vibrations and its FFT analysis.

scientists and engineers from the Cracow University of Technology to design and build the vibration monitoring system. The basis for building the monitoring system was to understand the phenomenon related to the propagation of vibration for shallow subways. The vibrations generated when the wheel comes into contact with the rail are propagated through the subway tunnel and ground, which are then transmitted to buildings located near the metro line. Some numerical and analytical solutions of the contact problem between the rail and wheel can be found in literature, for example, [16-19]. In these paper authors focused on experimental solution of the problem. A point of focus for the Warsaw Metro is the human perception of vibrations, but it is worth noting that for these shallow subways, vibrations are perceived to be larger on lower floors. This was the most critical observation which has contributed towards building the system. Human sensitivity to the vertical vibrations of floors, in some buildings located near metro line, was particularly evident in the preconstruction measurements. The sensitivity of individual floors depends on their dynamic characteristics, which is contingent on their floor structure, stiffness, and dimensions. These three factors made it necessary to select representative measurements points within buildings that are not always located close to the metro tunnel. Monitoring the human perception of vibrations of each metro train helps Warsaw Metro owners to determine which trains should continue operating and those that should not. This paper describes the observations and analysis of this monitoring system between 2003 and 2011.

After proper verification of the system developed by the authors, other proposals of systems appeared [20]. Another way for evaluation of the vibration impacts in the transport infrastructure environment was presented in [21].

\section{System Description}

The monitoring system was developed at the Institute of Structural Mechanics at Cracow University of Technology. This system allows for constant monitoring of vibrations. Based on the measured vibrations in three selected buildings, the identification of the technical condition of metro trains is performed. The vibrations generated when the wheel comes into contact with the rail are transferred through the tunnel structure and the ground, around the building, and close to the metro line. Previous experience shows that the

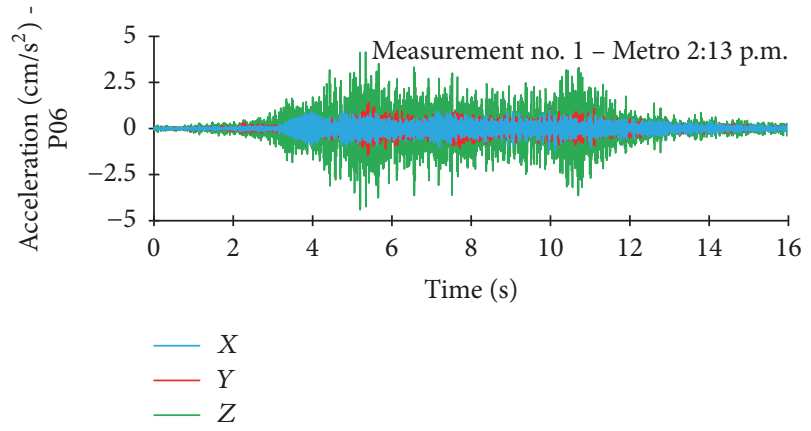

FIGURE 2: Relations between horizontal and vertical components of vibrations recorded at the ceiling of the building M22A.

wheel's profile has a significant influence on the level of vibrations. Therefore, these vibrations are a source of discomfort for the people in buildings close to the metro lines. The perception of vibrations by humans in the buildings is a complex problem, and it depends on, for example, the ceiling structure, its stiffness, and dimensions. Therefore, it is important to select the accurate, representative position of sensors in the buildings.

In the presented system, developed for the Warsaw metro line, the results of analysis, in relation to the comfort limits required for the people, constitute the criterion for evaluating the admissibility of the train for further operation [22]. Continuous monitoring of the vibration caused by each of the passing trains allows the individual trains to be eliminated before the vibration limit is reached. Moreover, these trains can be removed from operation before any complaint from the residents of the buildings near the subway line occurs. The accelerometer is mounted on the floor of the room in the building and is used to measure the vertical vibrations of the ceiling. Exemplary record of vertical component of the floor apartment vibrations and corresponding FFT are presented in Figure 1. Horizontal components were also measured but the level of maximum values of vibrations is smaller compared with the vertical component (see Figure 2). The results of analyses concerning these components are therefore not presented at work. It can be found in the [22], where data not presented in the paper was showed.

Signal vibration is triggered by the signal transmitted (wireless) from the measuring point located in the tunnel, triggering the registration with a photocell when passing a 


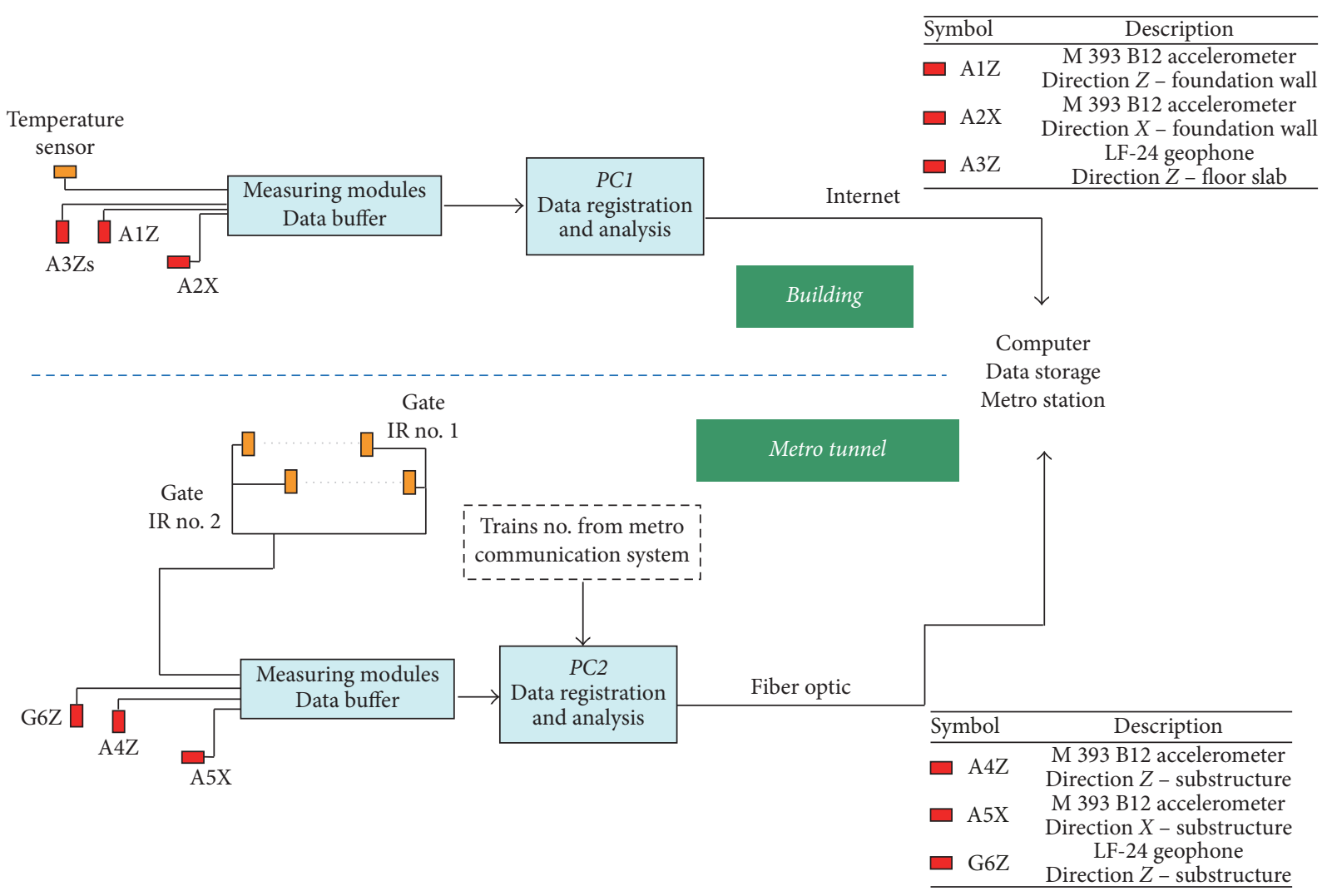

FIgURE 3: General plan of the system.

subway train. The system also records the speed of train. The vibration monitoring system consists of two independent measuring sys, each of which consists of two measuring stations. One station is located in a residential building and the other in the underground tunnel under the building. Every single passage of metro train was registered and considered in the analysis. Metro passages were identified by photocell monitoring in metro tunnels. Figure 3 shows the block diagram of complete monitoring system with all the sensors. In this paper we consider only human vibration comfort inside buildings. The sensor which is responsible for this parameter is only A3Zs mounted in the middle of the ceiling of the cellar. As in the system and during our measurement activities, we use the same reference system: $X$ direction is always horizontal and perpendicular to the source of vibrations, $Y$ is horizontal and parallel to the source of vibrations, and $Z$ direction is vertical. From the beginning the assumption in the monitoring system was to get data from $X$ direction with respect to the building vibration influence (A2X sensor) corresponding to the data from the tunnel (A5X). Another assumption was to get data of vertical vibrations from the building (A1Z) and tunnel (A4Z). These calculations are not presented in this paper.

In the system high sensitivity seismic accelerometers type PCB 393B12 are used, with the sensitivity on the level of $10 \mathrm{~V} / \mathrm{g}$ $( \pm 0,5 \mathrm{~g}$ range) and frequency range from $0,15 \mathrm{~Hz}$ till $1 \mathrm{kHz}$ $( \pm 5 \%)$. Sampling rate is set on $400 \mathrm{~Hz}$ which is adequate for studied problem and it fulfils the Nyquist's condition. Noise level is much lower than signal from metro train (compare Figures 1(a) and 2)

Registered data is transferred to the central unit. Then, the following analyses are performed:

(i) calculation of RMS (root means square) values in one-third bands and comparing them with assumed thresholds,

(ii) determining peaks in one-third bands octave and comparing them with assumed thresholds,

(iii) determining the maximum value from the entire time sequence,

(iv) generating a report.

The results are presented as WODL ratios. The WODL ratio (in English, the human vibration perceptivity ratio), proposed in [23] and in Polish code [24], is the measure of vibration perception by people. It is the maximum ratio of the acceleration RMS value, obtained from the analysis of the acceleration RMS value, equivalent to the threshold for the perception of vibration by humans (in the same $1 / 3$ octave band), chosen from each $1 / 3$ octave band, comp. equation (1).

The advantage of such a coefficient is that the result of the analysis from the frequency band is not independent, since the WODL indicates directly how many times the threshold for human vibration has been exceeded.

$$
\mathrm{WODL}=\max \left(\frac{a_{\mathrm{RMS}}}{a_{z}}\right),
$$




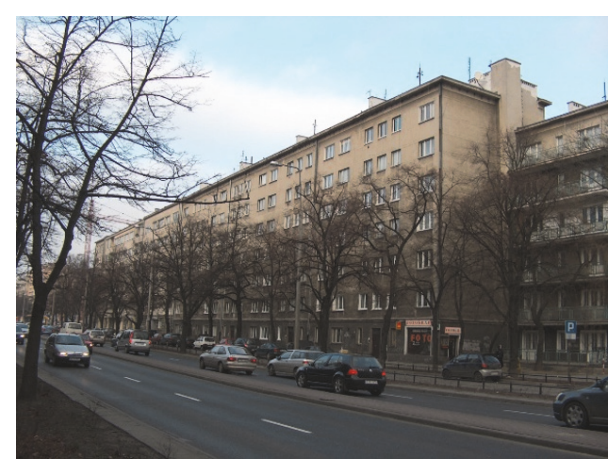

(a)

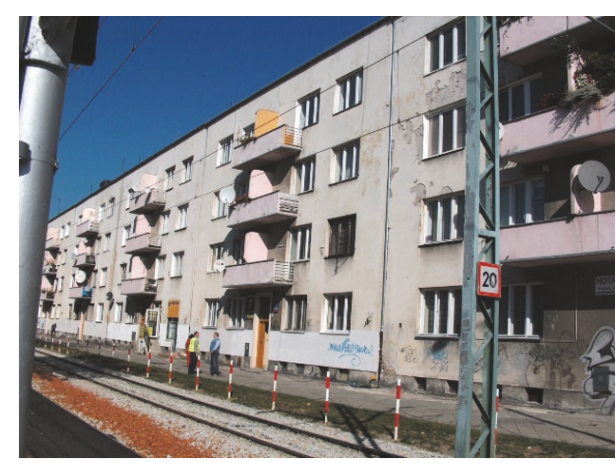

(b)

Figure 4: General view of the buildings: (a) N118 and (b) M22.

where $a_{\mathrm{RMS}}$ is acceleration RMS value obtained from analysis; $a_{z}$ is acceleration RMS value equivalent to the threshold for the perception of vibration in a $z$ direction in the same $1 / 3$ octave band as in $a_{\mathrm{RMS}}$.

Frequency values corresponding to $1 / 3$ octave bands used in analysis are equal to $1.25,1.6,2,3.16, \ldots, 63,80,100$ and listed also in Table 3 of ISO standard [25].

WODL ratios are coefficients calculated according to (1) using RMS basic procedure described in Polish standards [24, 26] and in ISO standard [27]. Recorded signals are filtered using Butterworth low-pass filter with cut-off frequency of $120 \mathrm{~Hz}$ according to requirements described in Polish standard [24].

RMS method averages acceleration values in duration:

$$
a_{W}=\left[\frac{1}{T} \int_{0}^{T} a_{W}^{2}(T) d t\right]^{1 / 2}
$$

where $a_{W}(T)$ is weighted acceleration as a function of time $\left[\mathrm{m} / \mathrm{s}^{2}\right] ; T$ is the duration of measurement $[\mathrm{s}]$.

RMS is basic method of evaluation according to ISO standard [25]. For signals with high crest factor (greater than 9), occasional shocks and transient vibration additional evaluation method like VDV analysis or MTVV analysis are required. Vibrations recorded in metro monitoring system are signals without shocks and with crest factor below 9 that is why RMS method was chosen for analysis and WODL ratio illustrated in most friendly way the percentage of exceedance of perception threshold of vibration.

Measurements in metro system last 24 hours and about 350 dynamical events are registered per day (concerning the tracks closer to the building). Metro managements care about good relations with residents of the buildings located in zone of metro dynamic influences. Because of many complaints of residents, researchers decided to use duration time of single event according to Polish standard [24] in which duration of vibration is defined as time in which amplitudes are greater than 0.2 of maximum value of vibrations. Adoption of such procedure is more rigorous than using of the whole record of vibrations for analysis and results of analyses are more independent from arbitral decision where to start and stop analyses.

\section{Influence of Wheels Reprofiling on Human Vibrations in the Buildings}

In the case of determining the vibration comfort of people in buildings, the decision parameter is the maximum RMS values obtained in each one-third octave band from the analysis of the perceived human horizontal and vertical vibrations of the floors. The influence on the vertical vibration of the ceilings has been assumed, since the vibration measurements generated by the metro in Warsaw have indicated that people are more sensitive to vertical vibrations of the ceilings [22]. The distribution of these values in time can be important for drawing practical conclusions.

Exemplary results of the analysis are given in this section. The data presented below relates to the selected measurement point installed in building N118, as well as building M22 (see Figure 4). The N118 building is a masonry residential building built in the 1950s. The building has 7 storeys above ground level and a basement. The bearing walls are arranged in the longitudinal direction. In the horizontal plan the building is L-shaped. The dimensions of the building in plan are $25.4 \mathrm{~m}$ by $72.8 \mathrm{~m}$. The distance to the metro tunnel wall is $14.0 \mathrm{~m}$.

The M22 building was built in 1936 and survived World War II. It is a masonry residential building. The building has four storeys above ground level and a basement. The bearing walls are arranged in longitudinal direction. The ceiling above the basement is dense-ribbed, while those in the upper levels are Klein type. The dimensions of the building in plan are $18.9 \mathrm{~m}$ by $12.6 \mathrm{~m}$. The distance to the metro tunnel wall is $19.5 \mathrm{~m}$.

Currently, both buildings are being operated. Due to the function they perform they are subject to regular reviews. Their technical condition is maintained in proper condition. The sensor installed in the building is also regularly monitored and calibrated. The results of our experimental investigations show that despite many years of influence of dynamic loads originating from metro line, there is no significant degradation of the buildings stiffness and their natural frequencies. Referring to the results of previous experiments $[14,19,22,23]$ the condition of the wheels is responsible for increasing vibrations in the buildings in the neighbourhood of metro line. 


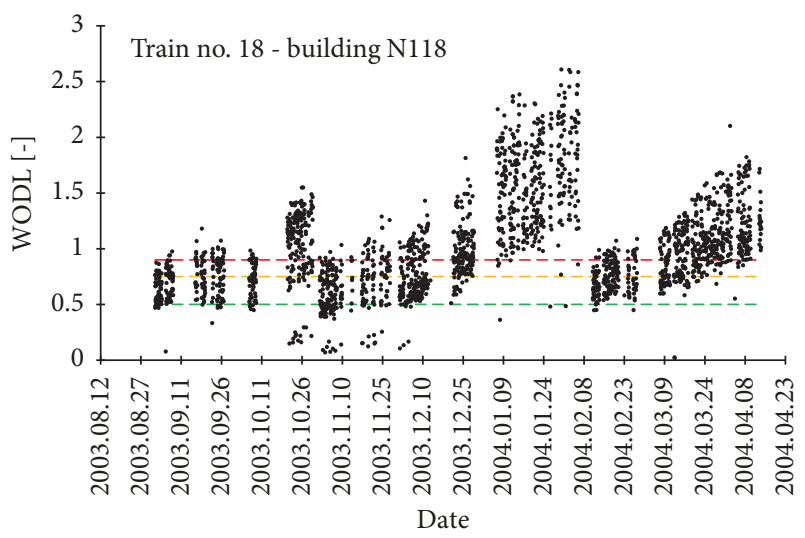

FIgURE 5: Distribution of WODL values for train number 18 in building N118.

We established that technical condition of the building, ground properties, and the metro tunnel itself are unchangeable in contrary to wheels' condition.

WODL indicator shows the real influence of vibrations on people inside buildings without calculating floors parameters; the results come from real measurements. The main idea of this parameter is to measure vibration comfort inside buildings. It is not necessary to calculate floors parameters; it is just diagnostics indicator. When measuring hundreds of floors, it is impossible to calculate all of their constructions, but using WODL indicator we can in a relative short time qualify if the human vibration comfort is exceeded or it is normative according to the standard.

Each of the recorded vertical vibrations of the ceiling is automatically analyzed, according to the Polish code [24], based on the experienced vibration by people. In this section, a more detailed analysis is presented on the daily distribution for the sensor located on the ceiling. Each passing of the train is represented by a single point. Within one day, the same train may pass by a sensor many times. There are also days (or weeks) when a train is not in use; therefore, there is no sensor registration for this train. The individual coloured lines in the graphs indicate the threshold values defined in the system:

(i) green, 50\% limit value of the defined threshold,

(ii) yellow, 75\% limit value of the defined threshold,

(iii) red, $90 \%$ limit value of the defined threshold.

The selected train (number 18) was analyzed from 2003 to 2011. Figures 5 and 6 present exemplary results from the continuous Warsaw Metro vibration monitoring system for the chosen Metropolis trains. The results presented in Figure 5 were recorded for 8 months (from September 2003 to April 2004).

More recent results from 2008 (excluding 2009, no data for continuous monitoring of vibration) until February 2011 are presented in Figure 6. The longer the train is in operation, the greater the difference is in WODL value for each day (see Figure 5). This indicates an increase in radial defects of the wheels. If the train's wheels reprofile, the daily values of the WODL coefficient are more consolidated in the chart.

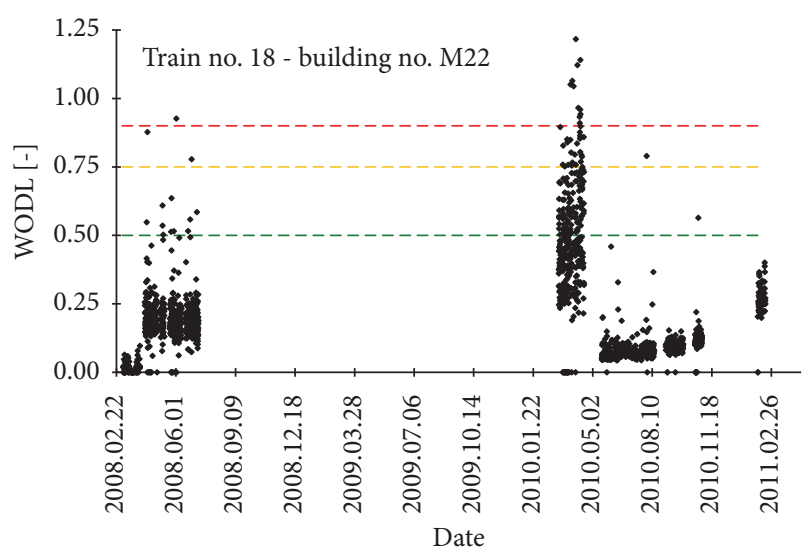

FIGURE 6: Distribution of WODL values for train number 18 in building M22A.

TABLE 1: Equations of trend function for the examined train compositions.

\begin{tabular}{|c|c|}
\hline Train number & Trend equation \\
\hline \multirow{5}{*}{18} & $y=0.0074 x-281.09$ \\
\hline & $y=0.0143 x-540.70$ \\
\hline & $\underline{y}=0.0102 x-387.20$ \\
\hline & $\bar{y}=0.0014 x-55.053$ \\
\hline & $y=0.0007 x-26.928$ \\
\hline
\end{tabular}

This was observed for all analyzed trains. It can be assumed that when the values of WODL are scattered and high, usually followed by a sudden decrease in value, it indicates a reprofiling of the wheels. Another characteristic of this reprofiling is manifested when the train presents high WODL values, with an increased quantity over a short period. As shown in Figure 5, the WODL value can change by more than one. Figure 6 shows the results for the M22A building for the previously presented subway train number 18, between March 2008 and April 2011. Based on the available data, the trend function values for the periods between wheel reprofiling were calculated. This data is presented in Table 1. In the table, the underlined equations indicate the trends from the 2003 to 2004 service life, while the remaining equations display the trends from 2008 to 2011 . This data was analyzed by calculating the mean value, standard deviation of mean value, and maximum and minimum values for the obtained trend equation coefficients (see Table 2). Linear functions were used to describe trends in specific time periods because of good fit, in most cases $R^{2}$ values are higher than 0.9 , and in other cases they are close to this value. This system is dedicated to use for engineers in their everyday tasks not only for scientific purposes. Liner trend was used in case to maximum simplify diagnostic conclusions and characterised good fit with values of the adjustment coefficients $R^{2}$ (in most cases higher than 0.9).

Based on the data collected from 2003 to 2004, the average value of $A$ was almost three times larger than in the period spanning from 2008 to 2011 (comp. Table 2). This 
TABLE 2: Statistical analysis of functions of all trends for particular time periods.

\begin{tabular}{|c|c|c|c|c|}
\hline \multirow{2}{*}{$\begin{array}{l}\text { Observation period } \\
\text { Equation coefficients }\end{array}$} & \multicolumn{2}{|c|}{ 2003-2004 } & \multicolumn{2}{|c|}{ 2008-2011 } \\
\hline & $A$ & $B$ & $A$ & $B$ \\
\hline Average value & 0.0088 & 341.58 & 0.0031 & 122.29 \\
\hline Standard deviation & 0.0038 & 155.71 & 0.0039 & 155.11 \\
\hline Maximum value & 0.0151 & 664.81 & 0.0159 & 626.52 \\
\hline Minimum value & 0.0003 & 10.71 & 0.0002 & 9.41 \\
\hline
\end{tabular}

shows that vibrations increased about three times faster in the first period, with a similar standard deviation in both periods and a similar range of values (from 0.0003 to 0.0151 in the first period and from 0.0002 to 0.0159 in the second). The lower value of $B$, for the period 2008-2011, reflects the average level of vibration measured on the ceiling, comp. Table 2 . The average level of vibration for the analyzed period was lower than in the 2003-2004 period. The continuous monitoring system of the Warsaw metro has been operating since 2003. The data from 2009 illustrates a significant change in the use of monitoring systems. From the information obtained from the operators of the system, it has also changed the procedure of reprofiling the wheels in trains. At present, if the train is retracted for reprofiling, all the wheels are corrected in shape, not only those on the axle where the greatest deviations are found in the radial run measurements (e.g., in the first years of use of monitoring system). Such a procedure has contributed to a significant improvement in the protection against human perceived vibration in buildings. This is presented in the drawings from 2008 to 2011. The data from 2008 shows significant levels of WODL. The nature of the presented data in the following years differs from this trend and has been converted into visuals, for clarity and ease of use. This change was the result of closer monitoring of changes in trends in operating warehouses. This computer visualization was analyzed positively by the operators in the Warsaw Metropolis. Currently, the visual trend analysis is implemented in the latest version of the monitoring system (GUI version) and allows the system operator to create such charts for proper operation. Trend monitoring is very important in terms of operating costs, as it allows the user to schedule the necessary repairs in advance, while saving unnecessary overhaul costs.

In the next part of this chapter, the WODL coefficients were calculated as a function of time over the following eight months (for selected trains). The selection of trains for analysis was dictated by the long-time period between reprofiling. When this period was relatively short, the train was not suitable for long-term analysis (since the trend was difficult to estimate). The Metropolis trains are numbered 17, $18,19,20,24,25$, and 28 for detailed analysis. For each of the trains, the chart presents the analyzed time period, followed by a trend analysis for maximum and average WODL. To get a ratio to the design due to the estimation of dynamic influences, it was necessary to specify the envelope values of the WODL. This is the maximum achievable (experimental, not computationally) value that determines the real dynamic impact limit on the roof of the building to be

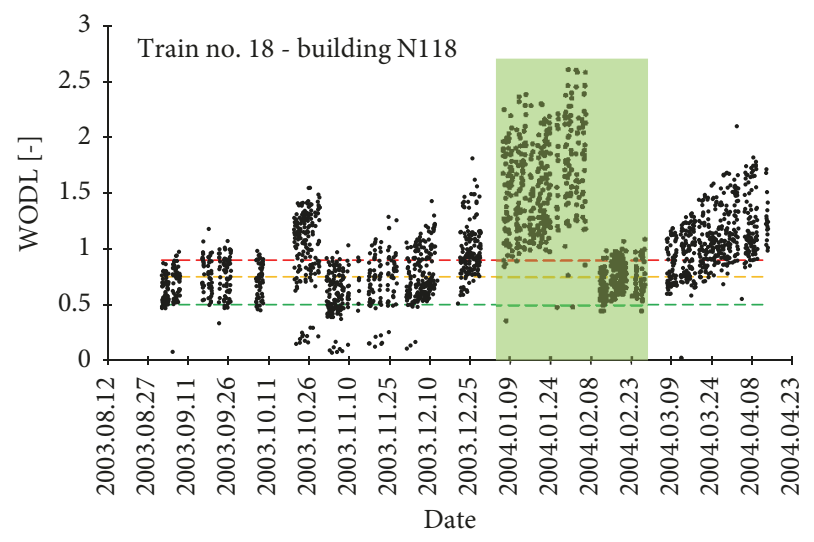

FIgURE 7: Time period for analysis of trends occurring during the crossings of selected subway train compositions.

measured. It can be used in the future as an indicator that has been determined based on measurements and can be used to determine the maximum possible dynamic impacts on building ceilings, which corresponds to human perceptions in buildings. Identifying the indicator is important, as there is a design trend that aims to estimate future adverse dynamic influences from individual sources of vibration, in the case of the design of buildings in the dynamic impact zone. This data is the result of experiential measurements, not from approximate calculations. In Figure 7 , there are the time periods for the individual trains, from which data are selected for further analysis. These are the periods between the wheel's reprofiling, when the WODL ratio increases. In the next step, the maximum value of the WODL and the average value are calculated for each day; the single point represents the max WODL for the day or the average WODL for the day. The results for train number 18 are presented in Figure 8, while the aggregate results for selected metro trains and the value of determination factor $R^{2}$ are presented in Table 3 .

The increase in WODL over the week ranges from about $0.9 \%$ to $1.8 \%$ and $R^{2}$ determines a range between $69.5 \%$ and $93.7 \%$. The conclusion is that adjusting the trend lines is not very advantageous especially for trains numbers $18,25,17$, and 19. To determine diagnostic indicators that could be used in building calculations in neighbourhoods of the metro line, an attempt should be made to narrow the dataset so as not to lose the most relevant value.

Due to the large spread of data and the desire to set a limit value for the most unfavorable, calculating the envelope of the maximum value of WODL seems intentional and 
TABLE 3: Aggregate results for envelope max WODL, for selected trains metro and value of determination factor $R^{2}$.

\begin{tabular}{lcccc}
\hline Number & Train number & Trend equation & $R^{2}$ & Increase WODL/week [\%] \\
\hline 1 & 17 & $y=0.0128 x$ & 0.8310 & 1.3 \\
2 & 18 & $y=0.0173 x$ & 0.6953 & 1.7 \\
3 & 19 & $y=0.012 x$ & 0.8308 & 1.2 \\
4 & 20 & $y=0.0154 x$ & 0.8834 & 1.5 \\
5 & 24 & $y=0.0154 x$ & 0.9181 & 1.5 \\
6 & 25 & $y=0.0095 x$ & 0.7989 & 0.9 \\
7 & 28 & $y=0.0177 x$ & 0.9367 & 1.8 \\
\hline
\end{tabular}

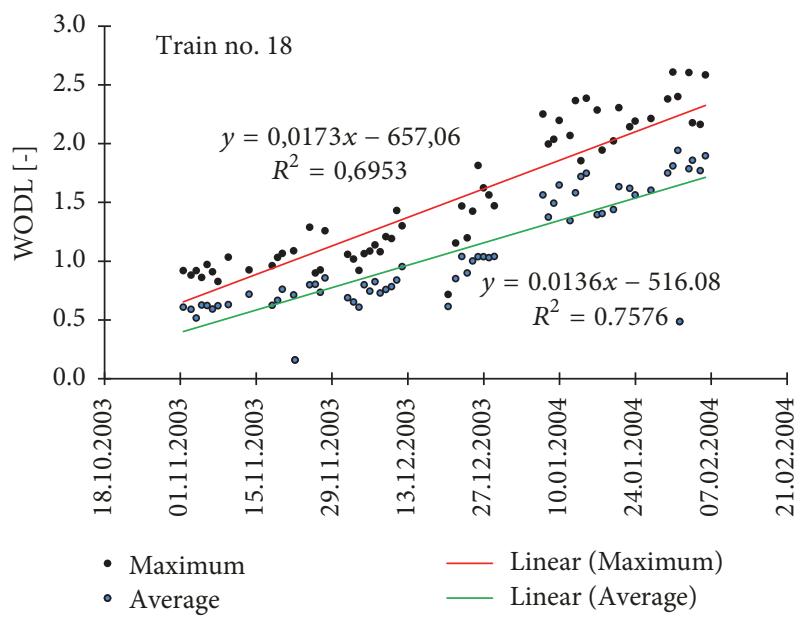

Figure 8: Trend line charts for envelope value max WODL together with function value.

appropriate. This analysis may be used in the future to predict the maximum possible dynamic impacts on people living in buildings close to the metro line. Figure 9 presents the WODL ratio envelope but in the uptrend.

Therefore, even in the following days, the WODL values were lower; they were omitted from the trend chart and only the next value if it was higher than the previous one. In conclusion, the WODL ratios do not exceed 3 (maximum for train number 18, ratio 2.6). Figure 10 presents the trend for the envelopes of increasing MAX WODL values from Figure 9.

The coefficient shows how much of the variation of the explanatory variable approximates the modeled phenomenon. It is a measure of the degree to which a model explains the development of an explanatory variable. It can also be said that the deterministic factor describes the part of the explanatory variable that results from its dependence on the explanatory variables included in the model. The coefficient of determination takes values from the range $[0 ; 1]$ if the model is free, and the least squares method is used to estimate the parameters. Its values are expressed in percentages. Model matching is the better, and the $R^{2}$ value is closer to unity. It is expressed as

$$
R^{2}=\frac{\sum_{t=1}^{n}\left(\hat{y}_{t}-\overline{y_{t}}\right)^{2}}{\sum_{t=1}^{n}\left(y_{t}-\overline{y_{t}}\right)^{2}},
$$

where $y_{t}$ is the actual value of variable $y$ at time $t, \hat{y}_{t}$ is theoretical value of the explanatory variable $y$ (based on the model); $\overline{y_{t}}$ is the arithmetic mean of the empirical values of the explanatory variable.

Weekly WODL increments range from $1 \%$ to $2 \%$ and the $R^{2}$ determinate range is from $92.3 \%$ to $98.1 \%$ (see Table 3 ). In summary, it is possible to assume for the most unfavorable situation which may occur in the future during the operation of subway trains in Warsaw, the increase of WODL is 2\% (see Figure 10, for train number 18, and Table 4) and the WODL value 2.6 (see Figure 9, train number 18). Figure 3 shows the trend line for the WODL max envelope value with the value of the function, as well as the value of the determinant $R^{2}$. Percentages show the WODL of the calculated trend line per week (delta WAT/week). The data presented are summarized in Table 5 for all tested trains with a comparison for the WODL max envelope and WODL max in the table.

As can be seen the values of WODL increments are quite similar, while the value of the determinant $\left(R^{2}\right)$ varies considerably (see Table 5 ). This is caused by a large spread of data. By analyzing the envelope value of the maximum WODL value, it can be concluded that the fit of the model is much closer to value $1.0(100 \%)$.

\section{Rush Hours Effect}

First step in this kind of analysis was to define time of day in which rush hours in Warsaw Metro occur. Number of tickets that were bought on two metro stations, Raclawicka and Pola Mokotowskie, was used to estimate rush hours for first line of Warsaw metro. Analysis was made during working days and on Saturdays on data covering years 2003 and 2004. Based on these data rush hours on the test measuring profile are as follows:

(i) from Monday to Friday, morning rush hours from 7.00 till 8.00 a.m. and afternoon rush hours from 2.00 till 6.00 p.m.,

(ii) on Saturday, morning rush hours from 11.00 a.m. till 3.00 p.m. and afternoon rush hours from 5.00 p.m. till 6.00 p.m.

Because of differences between working days and weekends and because of smaller number of passengers during weekends, working days rush hours were chosen for monitoring as decisive. Exemplary results of daily distribution of 

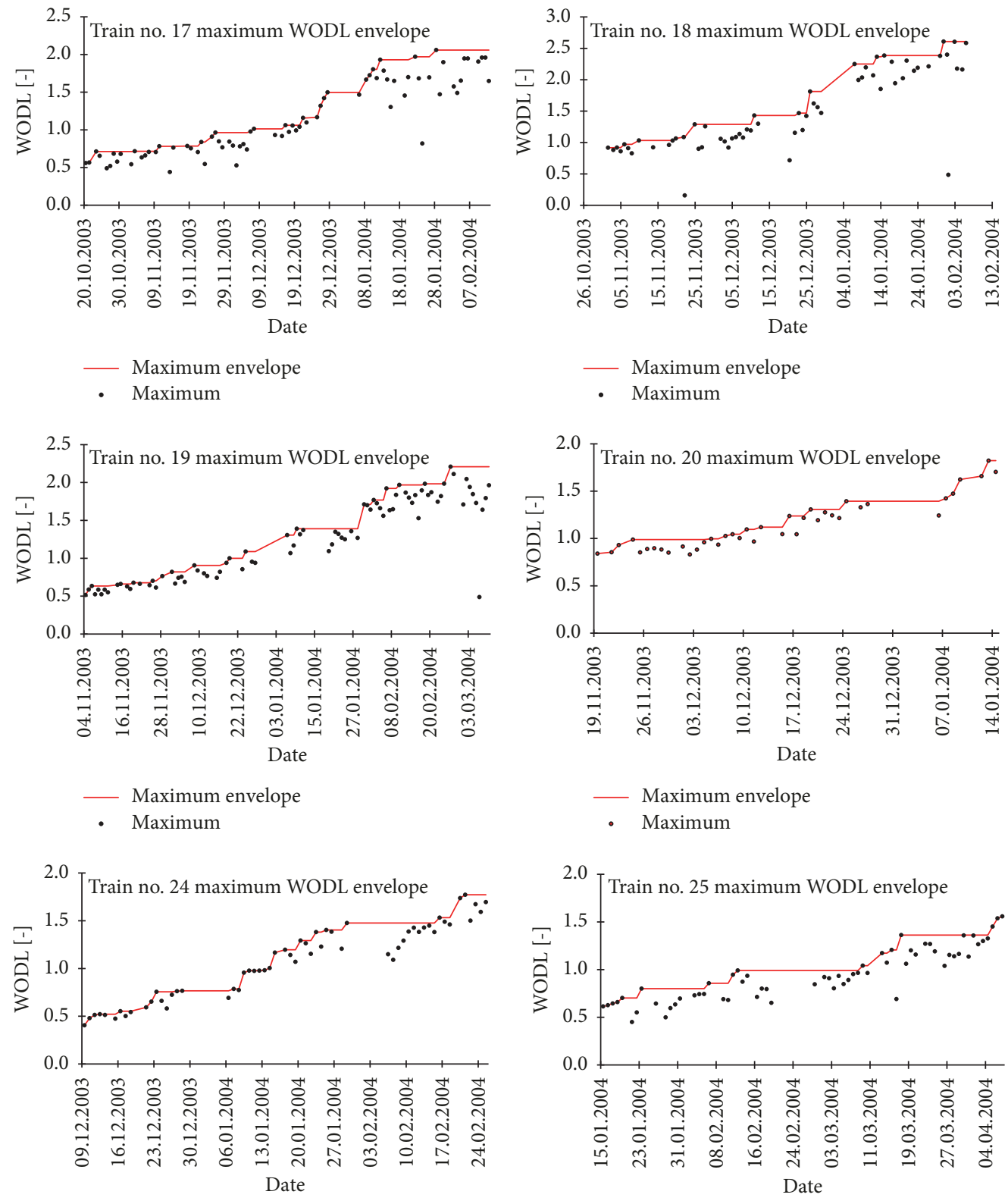

- Maximum envelope

- Maximum

- Maximum envelope

- Maximum

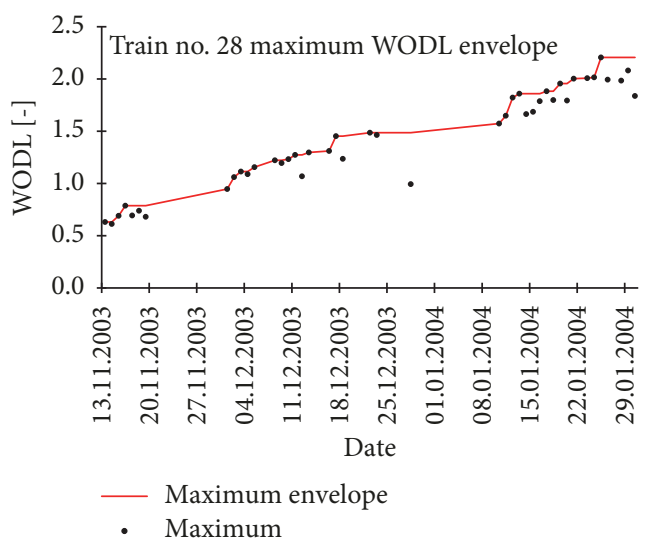

FIGURE 9: Envelope of maximum values of WODL in the upward trend. 


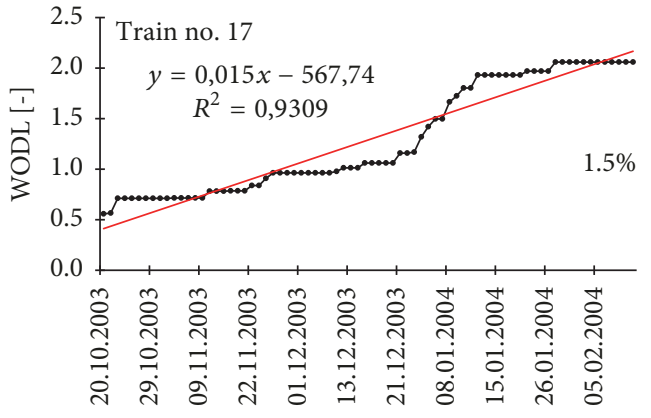

Date

— Maximum envelope

__ Linear (Maximum envelope)

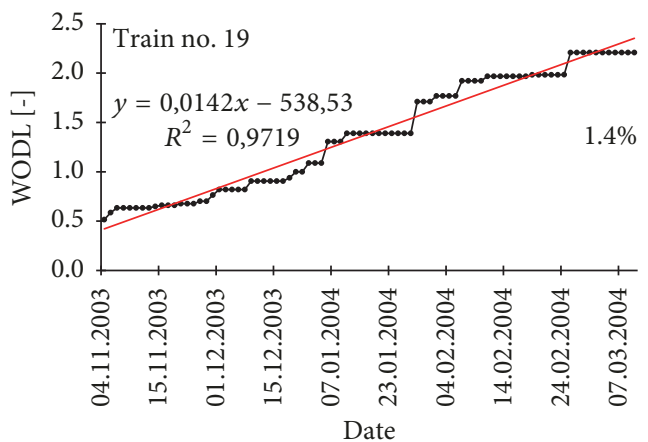

—- Maximum envelope

L Linear (Maximum envelope)

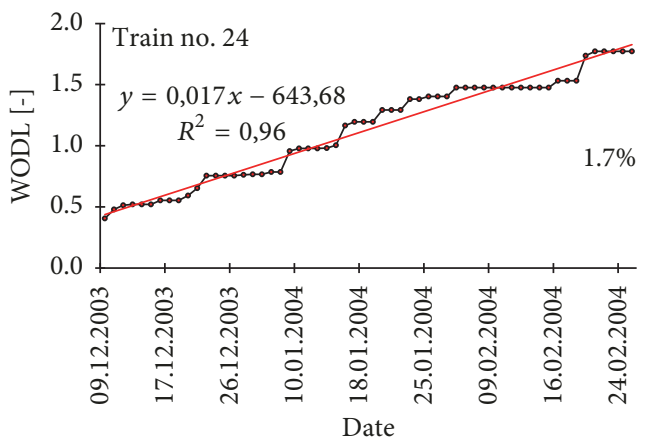

- Maximum envelope

__ Linear (Maximum envelope)

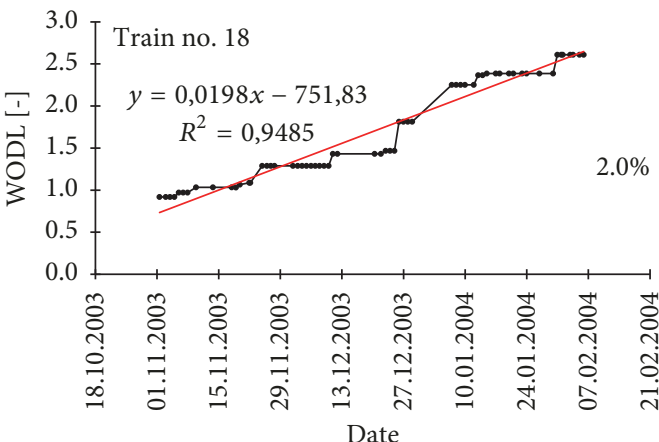

$$
\begin{aligned}
& \text { —- Maximum envelope } \\
& \ldots \text { Linear (Maximum envelope) }
\end{aligned}
$$

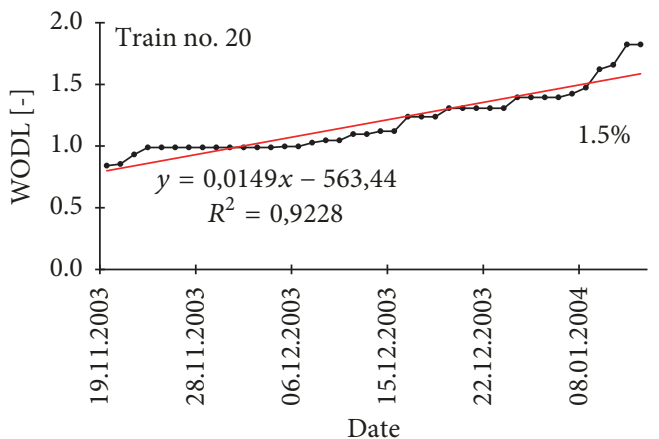

—- Maximum envelope

_ Linear (Maximum envelope)

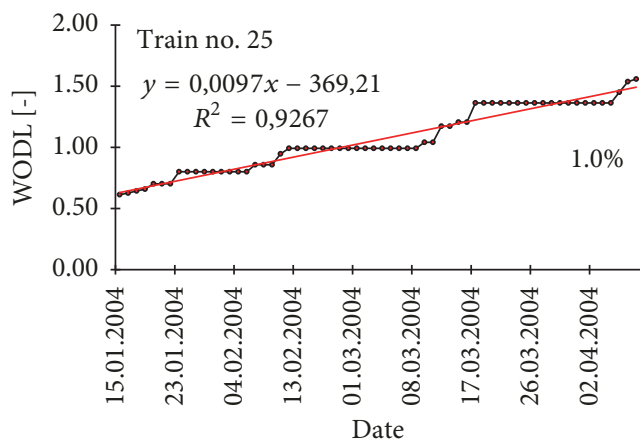

$\because$ Maximum envelope

_ Linear (Maximum envelope)

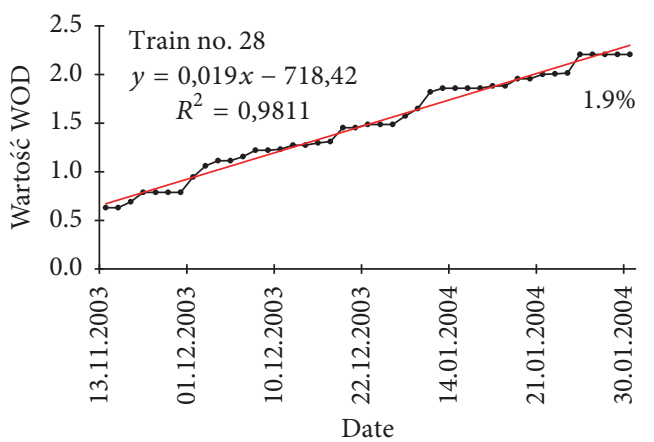

- Maximum envelope

__ Linear (Maximum envelope)

FIGURE 10: Envelope of the maximum values of WODL in the upward trend with the trend line. 
TABLE 4: Results for envelope max WODL, for selected trains metro.

\begin{tabular}{lcccc}
\hline Number & Train number & Trend equation & $R^{2}$ & Increase WODL/week [\%] \\
\hline 1 & 17 & $y=0.0150 x$ & 0.9309 & 1.5 \\
2 & 18 & $y=0.0198 x$ & 0.9485 & 2.0 \\
3 & 19 & $y=0.0142 x$ & 0.9719 & 1.4 \\
4 & 20 & $y=0.0149 x$ & 0.9228 & 1.5 \\
5 & 24 & $y=0.0170 x$ & 0.9600 & 1.7 \\
6 & 25 & $y=0.0097 x$ & 0.9267 & 1.0 \\
7 & 28 & $y=0.0190 x$ & 0.9811 & 1.9 \\
\hline
\end{tabular}

TABLE 5: Results for envelope max WODL, for selected subway train compositions.

\begin{tabular}{cccccccc}
\hline \multirow{2}{*}{ Number } & Train number & \multicolumn{3}{c}{ Maximum WODL } & \multicolumn{3}{c}{ Maximum WODL envelope } \\
& & Trend equation & $R^{2}$ & Increase WODL/week [\%] & Trend equation & $R^{2}$ & Increase WODL/week [\%] \\
\hline 1 & 17 & $y=0.0128 x$ & 0.8310 & 1.3 & $y=0.0150 x$ & 0.9309 & 1.5 \\
2 & 18 & $y=0.0173 x$ & 0.6953 & 1.7 & $y=0.0198 x$ & 0.9485 & 2.0 \\
3 & 19 & $y=0.012 x$ & 0.8308 & 1.2 & $y=0.0142 x$ & 0.9719 & 1.4 \\
4 & 20 & $y=0.0154 x$ & 0.8834 & 1.5 & $y=0.0149 x$ & 0.9228 & 1.5 \\
5 & 24 & $y=0.0154 x$ & 0.9181 & 1.5 & $y=0.0170 x$ & 0.9600 & 1.7 \\
6 & 25 & $y=0.0095 x$ & 0.7989 & 0.9 & $y=0.0097 x$ & 0.9267 & 1.0 \\
7 & 28 & $y=0.0177 x$ & 0.9367 & 1.8 & $y=0.0190 x$ & 0.9811 & 1.9 \\
\hline
\end{tabular}

maximum value of WODL coefficient for train number 18 recorded in January 2004 on building N118 are shown in Figure 11.

Average values of WODL coefficient for train number 18 for different time of day: morning, rush hours and evening are listed in Table 6. In this table date of measurement and number of trains passing during the day is also listed.

In thirteen days from working days during January 2004 average value of WODL is higher during rush hours than in the morning, and in twelve days average WODL values were higher during rush hours than in the evening. The total average value calculated for whole month also shows that WODL coefficient is higher for rush hour than beyond them. What is interesting this difference between average value of WODL is higher comprising rush hours to the evening than to the morning, but the highest value of WODL occurs in the evening not in the rush hours.

Between 6 and 10 of February wheels of train number 18 were rolled which of course effect on WODL results. Daily distribution after this renovation is shown in Figure 12 and average values of WODL are listed in Table 7.

The main observation is that renovation of wheels has much higher influence on WODL values than rush hours effect. Which is proper for diagnosis of wheel train condition, and which was assumption of monitoring system in Warsaw Metro.
Total average value calculated for whole February is higher for rush hours but differences between rush hours and the other time of day are not as significant as it was before wheels were rolled. Comparing days in which during rush hours average value of WODL was higher than in other time of the day it can be seen that

(i) only during 5 days WODL is higher during rush hours than in the morning, during two days this value is the same, and during 5 days WODL is lower during rush hours than in the morning,

(ii) during 7 days WODL is higher during rush hours than in the evening and during two days this value is the same,

(iii) difference between the total average value of WODL during rush hours and in the evening is again higher than difference between rush hours and morning.

Before and after renovation of train wheels average values of WODL are higher (but not very significant) during the rush hours than for other time of day. These differences are in both cases higher when rush hours are compared with the evening. Standard deviation for rush hours is higher than for the other daytime. This all suggest that train filled with passengers can give higher human perception of vibration residing in buildings located close to metro line.

Rush hours in Warsaw Metro are not estimated precisely which could be a reason of relatively small differences 
TABLE 6: Average values of WODL for different time of day, train number 18.

\begin{tabular}{|c|c|c|c|c|c|}
\hline \multirow{2}{*}{ Number } & \multirow{2}{*}{ Date } & \multirow{2}{*}{ Number of drives } & \multicolumn{3}{|c|}{ Average WODL } \\
\hline & & & Morning & Rush hour & Evening \\
\hline 1 & 2004-01-06 & 12 & 1.83 & 1.65 & 1.34 \\
\hline 2 & 2004-01-07 & 19 & 1.36 & 1.19 & 1.52 \\
\hline 3 & 2004-01-08 & 19 & 1.48 & 1.76 & 1.33 \\
\hline 4 & 2004-01-09 & 19 & 1.70 & 1.76 & 1.50 \\
\hline 5 & 2004-01-11 & 18 & 1.52 & 1.08 & 1.20 \\
\hline 6 & 2004-01-12 & 34 & 1.70 & 1.15 & 1.57 \\
\hline 7 & 2004-01-13 & 13 & 1.73 & 1.68 & 1.74 \\
\hline 8 & 2004-01-14 & 18 & 1.49 & 1.90 & 2.08 \\
\hline 9 & $2004-01-16$ & 18 & 1.26 & 1.38 & 1.65 \\
\hline 10 & 2004-01-17 & 14 & 1.63 & 1.23 & 1.11 \\
\hline 11 & 2004-01-19 & 19 & 1.49 & 1.54 & 1.29 \\
\hline 12 & 2004-01-20 & 19 & 1.60 & 1.68 & 1.65 \\
\hline 13 & 2004-01-21 & 18 & 1.47 & 1.73 & 1.66 \\
\hline 14 & 2004-01-22 & 18 & 1.69 & 1.78 & 1.42 \\
\hline 15 & 2004-01-23 & 19 & 1.56 & 1.75 & 1.51 \\
\hline 16 & 2004-01-26 & 15 & 1.43 & 1.68 & 1.84 \\
\hline 17 & 2004-01-29 & 19 & 1.79 & 1.96 & 1.55 \\
\hline 18 & 2004-01-30 & 18 & 1.72 & 1.93 & 1.78 \\
\hline \multirow[t]{5}{*}{19} & 2004-01-31 & 14 & 1.96 & 1.97 & 1.88 \\
\hline & \multicolumn{2}{|c|}{ Average value } & 1.60 & 1.62 & 1.56 \\
\hline & \multicolumn{2}{|c|}{ Standard deviation } & 0.1739 & 0.2820 & 0.2463 \\
\hline & \multicolumn{2}{|c|}{ Maximum value } & 1.96 & 1.97 & 2.08 \\
\hline & \multicolumn{2}{|c|}{ Minimum value } & 1.26 & 1.08 & 1.11 \\
\hline
\end{tabular}

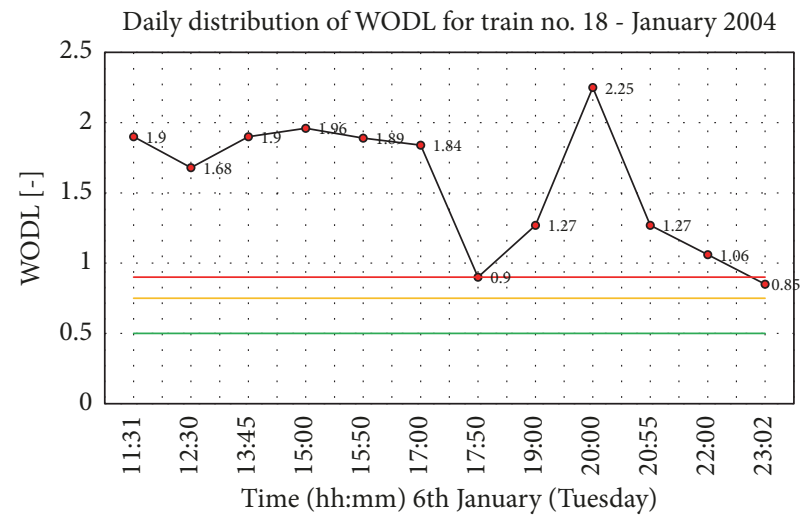

Daily distribution of WODL for train no. 18 - January 2004

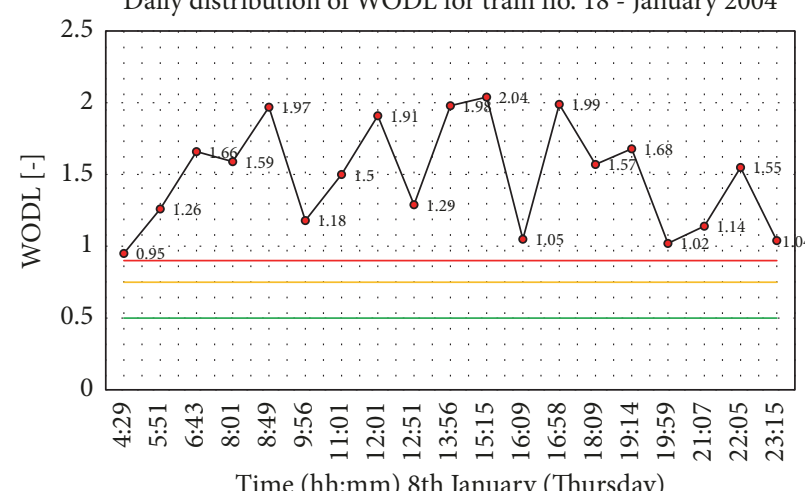

Daily distribution of WODL for train no. 18 - January 2004

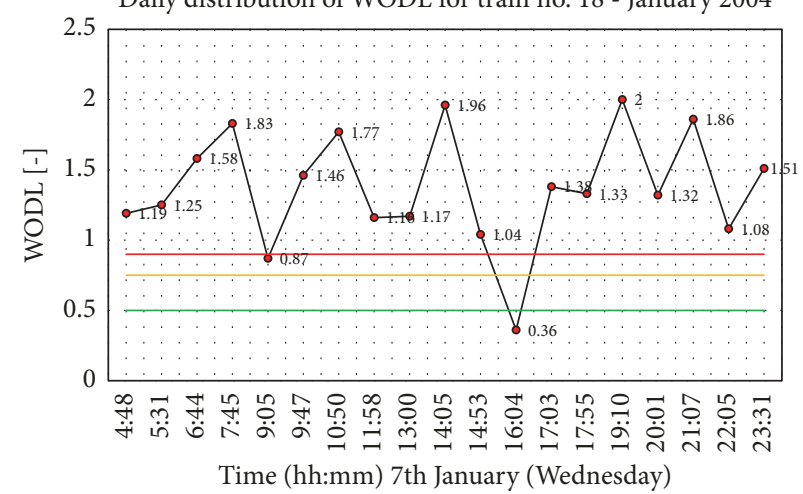

Daily distribution of WODL for train no. 18 - January 2004

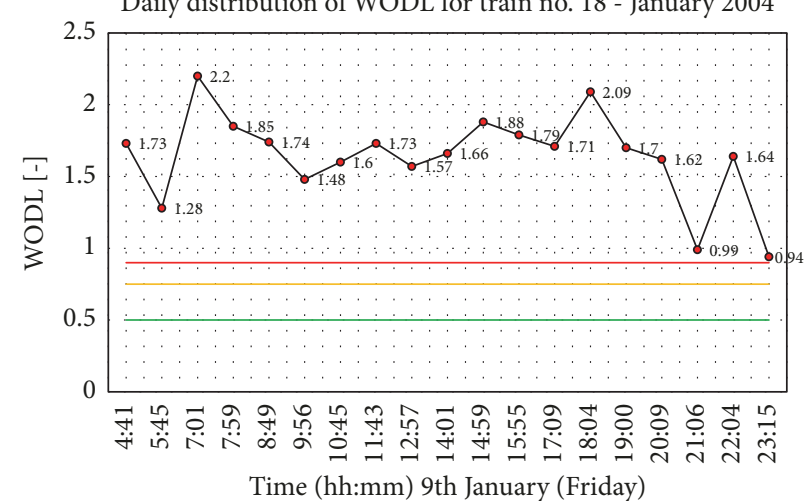

FIGURE 11: Daily distribution of maximum WODL value for train number 18. 


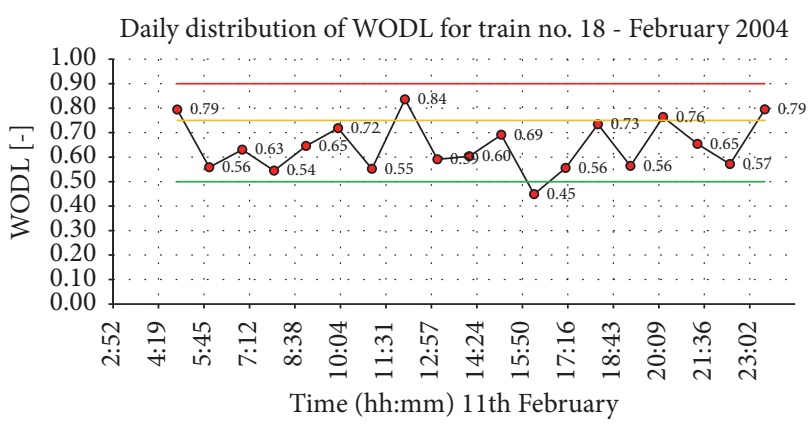

Daily distribution of WODL for train no. 18 - February 2004
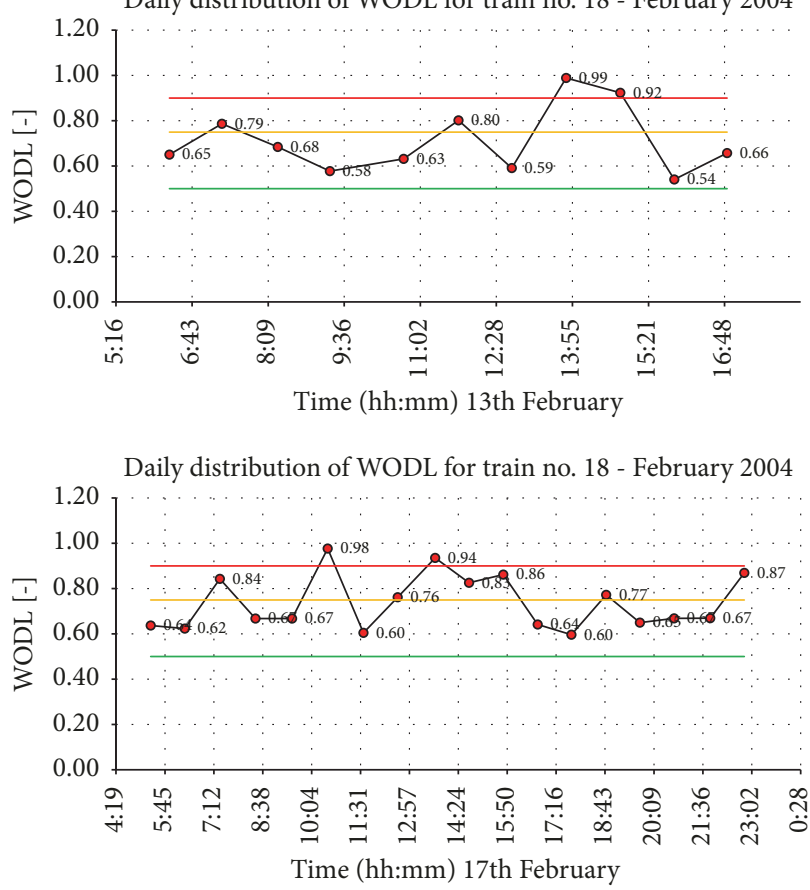

Daily distribution of WODL for train no. 18 - February 2004
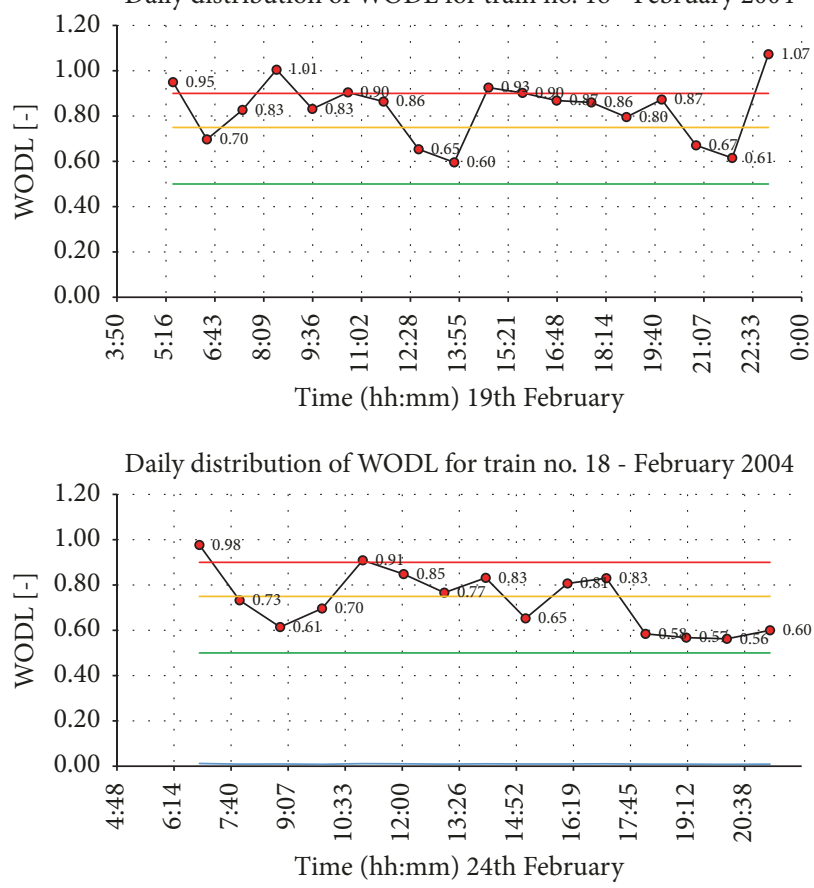

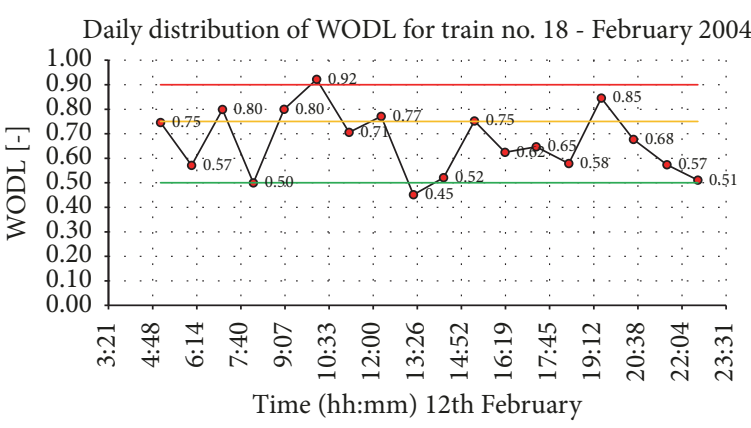

Daily distribution of WODL for train no. 18 - February 2004
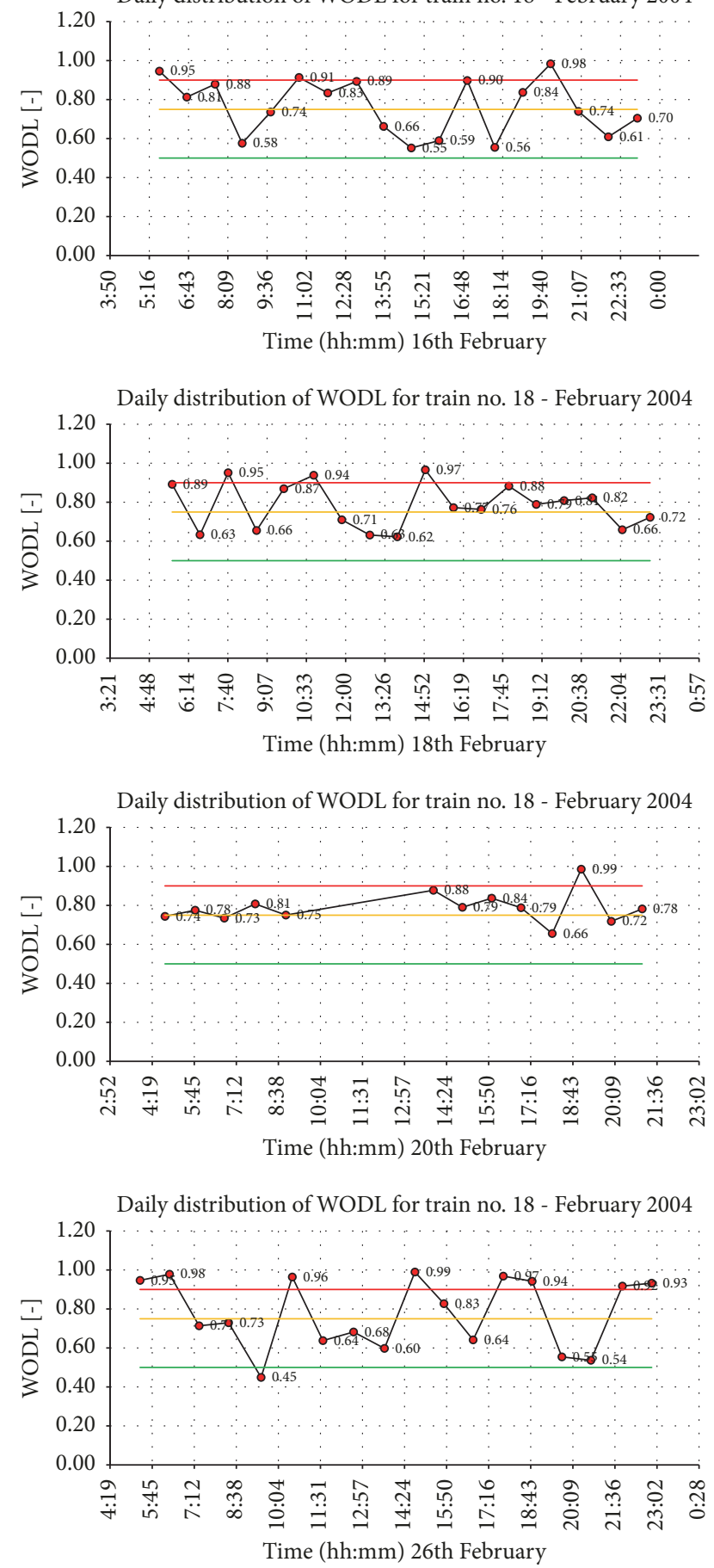

FIgURE 12: Continued. 


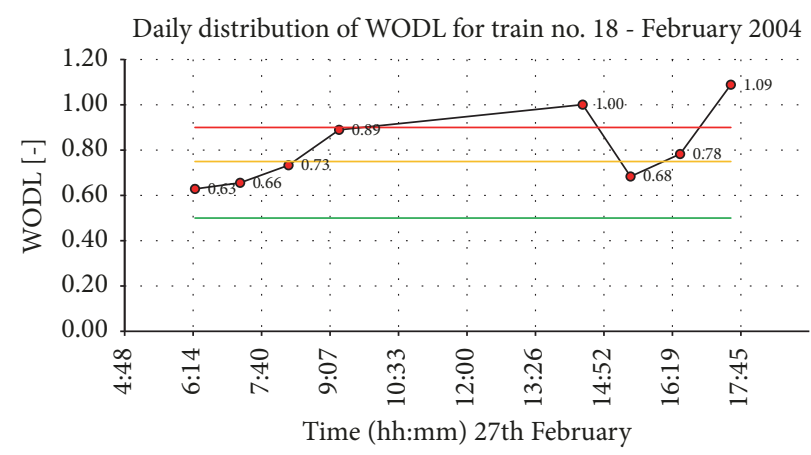

FIGURE 12: Daily distribution of maximum WODL value for train number 18 after wheel renovation.

TABLE 7: Average values of WODL for different time of day after wheels renovation, train number 18.

\begin{tabular}{|c|c|c|c|c|c|}
\hline \multirow{2}{*}{ Number } & \multirow{2}{*}{ Date } & \multirow{2}{*}{ Number of drives } & \multicolumn{3}{|c|}{ Average WODL } \\
\hline & & & Morning & Rush hour & Evening \\
\hline 5 & 2004-02-11 & 19 & 0.65 & 0.57 & 0.68 \\
\hline 6 & 2004-02-12 & 18 & 0.70 & 0.64 & 0.64 \\
\hline 7 & $2004-02-13$ & 11 & 0.71 & 0.71 & 0.64 \\
\hline 8 & 2004-02-15 & 18 & 0.73 & 0.68 & 0.74 \\
\hline 9 & $2004-02-16$ & 18 & 0.81 & 0.65 & 0.77 \\
\hline 10 & 2004-02-17 & 18 & 0.75 & 0.73 & 0.73 \\
\hline 11 & 2004-02-18 & 18 & 0.77 & 0.85 & 0.76 \\
\hline 12 & 2004-02-19 & 18 & 0.81 & 0.89 & 0.81 \\
\hline 13 & $2004-02-20$ & 13 & 0.78 & 0.81 & 0.79 \\
\hline 14 & $2004-02-24$ & 15 & 0.78 & 0.78 & 0.58 \\
\hline 15 & $2004-02-26$ & 18 & 0.78 & 0.86 & 0.78 \\
\hline \multirow[t]{5}{*}{16} & 2004-01-27 & 8 & 0.73 & 0.89 & 0.78 \\
\hline & \multicolumn{2}{|c|}{ Average value } & 0.75 & 0.76 & 0.73 \\
\hline & \multicolumn{2}{|c|}{ Standard deviation } & 0.0479 & 0.1074 & 0.0729 \\
\hline & \multicolumn{2}{|c|}{ Maximum value } & 0.81 & 0.89 & 0.81 \\
\hline & \multicolumn{2}{|c|}{ Minimum value } & 0.65 & 0.67 & 0.58 \\
\hline
\end{tabular}

between morning and rush hours. This indicates that morning rush hours should be specified during more precise measurements.

\section{Conclusions}

In the paper the monitoring system in Warsaw metro was presented. Since 2003, when the system was installed, many changes have been made in the operation and management of the metro.

Many advantages can be distinguished after the system was introduced. First of all, the number of complaints related to the negative impact of vibrations on people in nearby buildings has decreased. The main reason for these complaints was problems with wheel profiling. The level of these impacts and the rate of change were observed only after the system was installed. This significantly contributed to improving the comfort of use of buildings near the metro line.

The method of repairing wheels on trains has also been fundamentally changed. During the first period of system operation, only the wheels with the largest damage were repaired, which did not give good results. The system introduced the principle of repairing all wheels on the train, which improved comfort and contributed to the extension of the period between subsequent repairs.

The system also allowed better planning of repairs. Thanks to the introduced alarm levels in the system, it is possible to plan repairs for individual trains. It also allows for better planning of costs and organization of costs. The measurement system together with the software allows you to make decisions that affect the image of the metro manager in an easy and quick way and enables the rationalization of costs. 
The vibration monitoring system introduced on the first metro line in Warsaw has fulfilled its role so well that it is currently being expanded on subsequent sections of the second metro line in Warsaw.

\section{Conflicts of Interest}

The authors declare that there are no conflicts of interest regarding the publication of the paper.

\section{References}

[1] B. Chen, Y. L. Xu, and X. Zhao, "Integrated vibration control and health monitoring of building structures: a time-domain approach," Smart Structures and Systems, vol. 6, no. 7, pp. 811$833,2010$.

[2] A. Deraemaeker, E. Reynders, G. De Roeck, and J. Kullaa, "Vibration-based structural health monitoring using outputonly measurements under changing environment," Mechanical Systems and Signal Processing, vol. 22, no. 1, pp. 34-56, 2008.

[3] J. M. W. Brownjohn, A. de Stefano, Y.-L. Xu, H. Wenzel, and A. E. Aktan, "Vibration-based monitoring of civil infrastructure: Challenges and successes," Journal of Civil Structural Health Monitoring, vol. 1, no. 3-4, pp. 79-95, 2011.

[4] A. Mita and S. Takhira, "A smart sensor using a mechanical memory for structural health monitoring of a damagecontrolled building," Smart Materials and Structures, vol. 12, no. 2, pp. 204-209, 2003.

[5] M. D. Kohler, P. M. Davis, and E. Safak, "Earthquake and ambient vibration monitoring of the steel-frame UCLA factor building," Earthquake Spectra, vol. 21, no. 3, pp. 715-736, 2005.

[6] R. D. Nayeri, S. F. Masri, R. G. Ghanem, and R. L. Nigbor, "A novel approach for the structural identification and monitoring of a full-scale 17-story building based on ambient vibration measurements," Smart Materials and Structures, vol. 17, no. 2, Article ID 025006, 2008.

[7] M. R. Kaloop, J. W. Hu, M. A. Sayed, and J. Seong, "Structural performance assessment based on statistical and wavelet analysis of acceleration measurements of a building during an earthquake," Shock and Vibration, vol. 2016, Article ID 8902727, 13 pages, 2016.

[8] H. Xia, J. Chen, P. Wei, C. Xia, G. De Roeck, and G. Degrande, "Experimental investigation of railway train-induced vibrations of surrounding ground and a nearby multi-story building," Earthquake Engineering and Engineering Vibration, vol. 8, no. 1, pp. 137-148, 2009.

[9] D. P. Connolly, G. Kouroussis, P. K. Woodward, P. A. Costa, O. Verlinden, and M. C. Forde, "Field testing and analysis of high speed rail vibrations," Soil Dynamics and Earthquake Engineering, vol. 67, pp. 102-118, 2014.

[10] H.-c. Guo, "Blasting Vibration Monitoring and Control Technology Applied in Construction of Huaishuping Tunnel," Tunnel Construction, 2006.

[11] M. Nefovska-Danilovic, M. Petronijevic, and B. Savija, "Trafficinduced vibrations of frame structures," Canadian Journal of Civil Engineering, vol. 40, no. 2, pp. 158-171, 2013.

[12] M. F. M. Hussein, Vibration from underground railways [Ph.D. Thesis], University of Cambridge, 2004.

[13] F. Pachla, B. R. Pawlik, K. Stypula, and T. Tatara, "Vibration induced by railway traffic-zones of influence on buildings and humans," in Proceedings of the 27th International Conference on Vibroengineering, vol. 13, pp. 188-192, September 2017.

[14] J. Kawecki, K. Koziol, and K. Stypula, "The Design of Rail Tracks including the Influence of Vibration on People in Buildings," in Proceedings of the The Eleventh International Conference on Computational Structures Technology, B. H. V. Topping, Ed., vol. 176, pp. 1-9, Dubrovnik, Croatia, September 2012.

[15] D. Makovicka, D. Makovicka Jr, and D. Makovička, "Analysis of Vibro-Isolated Building Excited by the Technical Seismicity of Traffic Effects," in Proceedings of the D. MakovičkaJr, vol. 2, pp. 64-69, 2016.

[16] A. Chudzikiewicz and J. Korzeb, "Simulation study of wheels wear in low-floor tram with independently rotating wheels," Archive of Applied Mechanics, vol. 88, no. 1-2, pp. 175-192, 2018.

[17] F. P. Bowden and D. Tabor, "The Area of Contact between Stationary and between Moving Surfaces," Proceedings of the Royal Society A Mathematical, Physical and Engineering Sciences, vol. 169, no. 938, pp. 391-413, 1939.

[18] R. Enblom and M. Berg, "Simulation of railway wheel profile development due to wear influence of disc braking and contact environment," Wear, vol. 258, no. 7-8, pp. 1055-1063, 2005.

[19] R. Ciesielski and K. Stypuła, "Influence of shape change of carriage wheels in consequence of exploitation wear on the level of building vibration caused by shallow underground train passages - case history," in Proceedings of Conference Structural Dynamics EURODYN 2002, Grundmann and Schuëller, Eds., pp. 313-316, Swets \& Zeitlinger, 2002.

[20] M. Nader and J. Korzeb, "Concept of a monitoring system for evaluation vibration, sound and another physical factors on construction and operation stages of metro line," in Proceedings of 4th International Conference on Experiments/Process/System/Modelling/Simulation/Optimization, vol. 1, pp. 158-164, 2011.

[21] J. Korzeb and A. Chudzikiewicz, "Evaluation of the vibration impacts in the transport infrastructure environment," Archive of Applied Mechanics, vol. 85, no. 9-10, pp. 1331-1342, 2015.

[22] P. Stecz, Effect of long-term dynamic loads generated by subway trains passes by [Ph.D. thesis], Cracow University of Technology, 2014.

[23] J. Kawecki and J. K. Stypula, "Providing vibration comfort for people in buildings exposed to impact of communication influences, Wydawnictwo PK," Wydawnictwo PK, Kraków, 2013.

[24] Standard PN-B-02171:2017-06, Evaluation of the impact of vibrations on people in buildings, (in Polish).

[25] ISO 2631-1, Mechanical vibration and shock - Evaluation of human exposure to whole-body vibration - Part 1: General requirements, 1997.

[26] Standard PN-B-02171:1988, Evaluation of the impact of vibrations on people in buildings, (in Polish).

[27] Standard ISO 2631-2, Guide to the evaluation of human exposure to whole body vibration. Part 2- Vibration in buildings, 2003. 


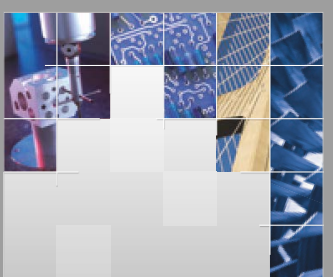

\section{Enfincering}
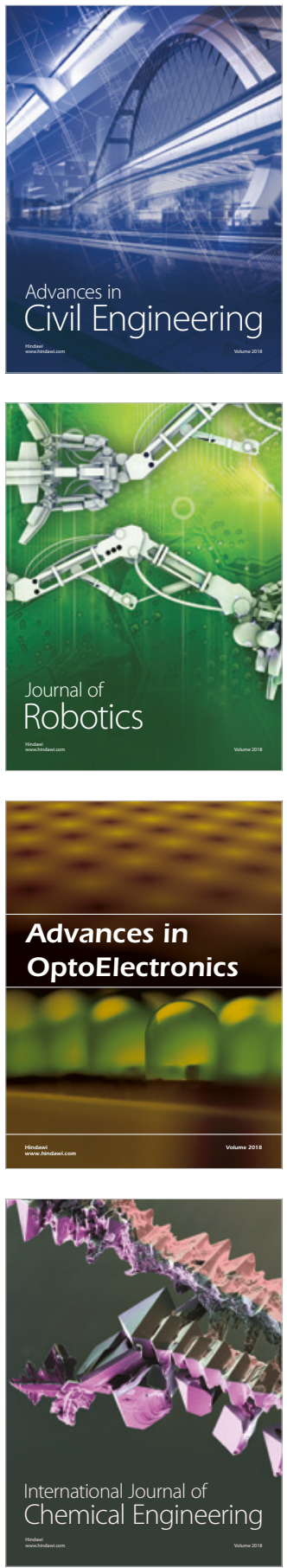

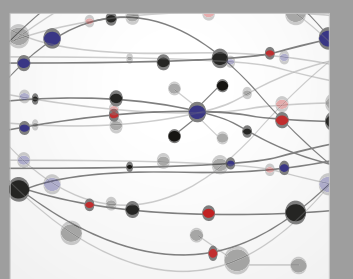

\section{Rotating \\ Machinery}

The Scientific World Journal

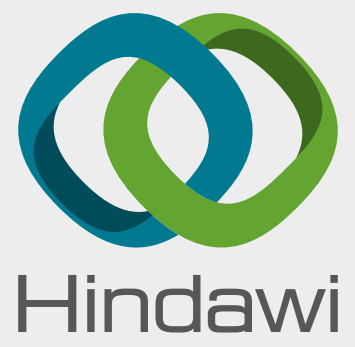

Submit your manuscripts at

www.hindawi.com
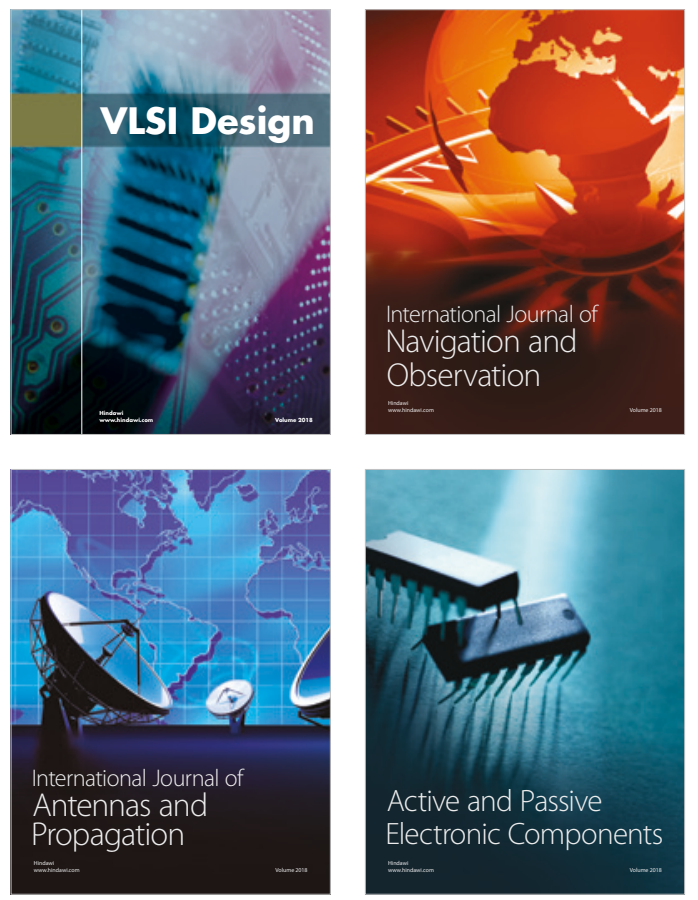
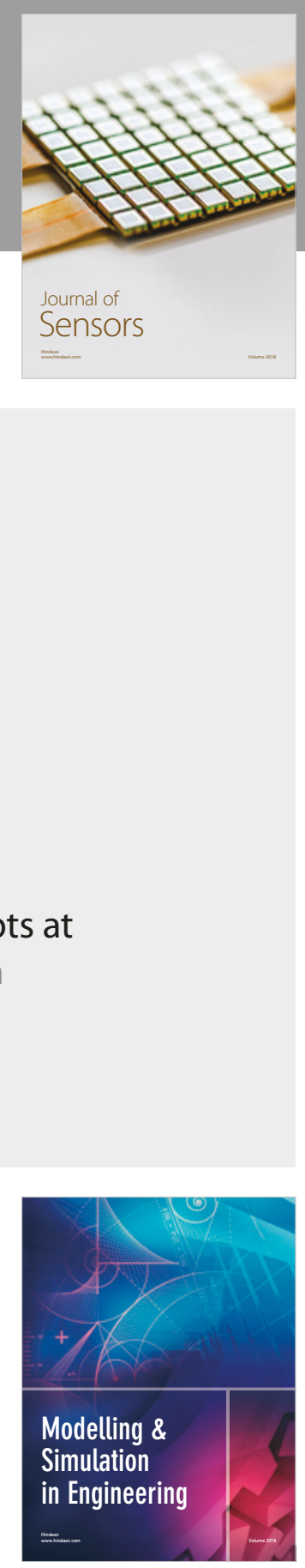

\section{Advances \\ Multimedia}
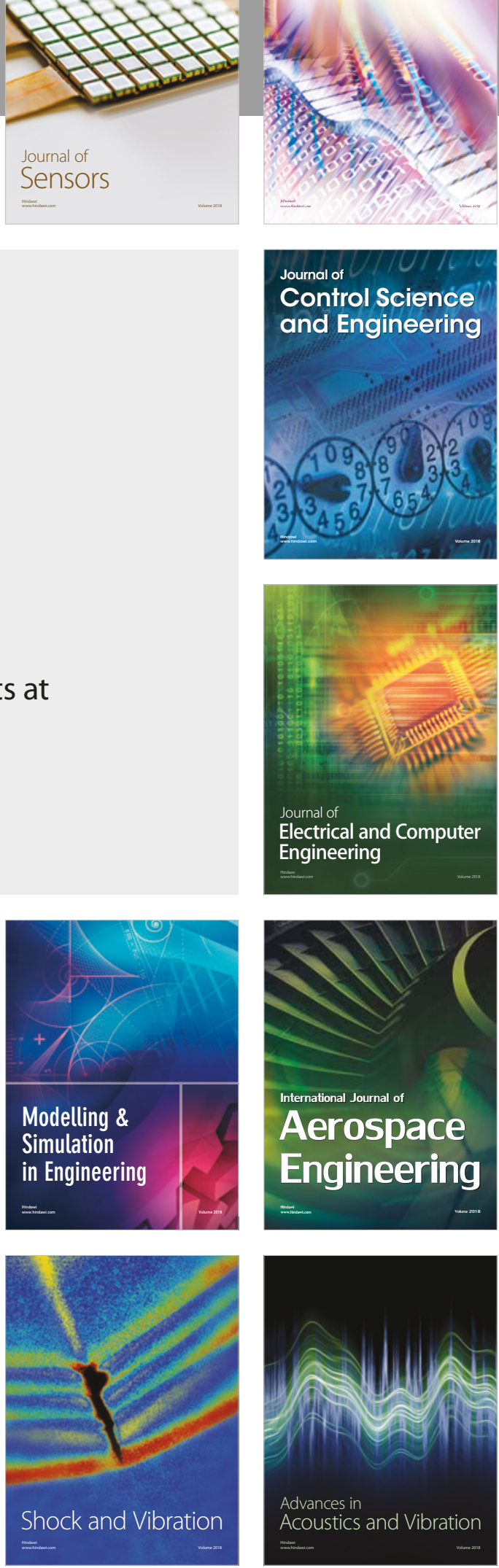